\title{
Tourism, culture and development: Hopes, dreams and realities in East Indonesia
}

By Stroma Cole. (Clevedon, UK: Channel View Publications), 2008, 264 pp. US\$119.95 (Hbk). ISBN-13 9781845410704. US\$49.95 (Pbk). ISBN-13 9781845410698.

This ethnography about emergent tourism development in remote villages on the island of Flores, Eastern Indonesia, evidences anthropologist Stroma Cole's long-time familiarity with both the tourism industry and the particularities of Ngadha culture. Her first contact with the villages was in 1989, when she started taking tourists there as a tour leader. Since then, Dr. Cole has kept on returning to Flores for frequent visits. This continued involvement has led to an engaged piece of scholarship. As she states in the beginning of the book, "I dot not believe in an ethnographer's neutrality. I am implicated in the material presented here, I have affected the self-image of the communities, and my presence and actions have impacted on the tourism development process" (11).

The monograph is divided into three parts. In the first section, the author reviews the anthropology of tourism, the different scales of tourism development, and Ngadha culture and society. Such an overview is particularly relevant for those readers not familiar with these topics. Since Dr. Cole is the Chairperson of Tourism Concern, an NGO campaigning on tourism's exploitative practices, one can expect a critical stance. She used her case study, for instance, to question bottom-up and community-based approaches to tourism development (58-61), arguing that "any tourism development strategy must be part of an integrated development strategy" (61). The author also demystifies the ideologies underpinning the naming of certain types of tourism as cultural, ethnic, or indigenous (61-63). While the large list of references proves the author is familiar with the literature, I was surprised she engages so little with critical tourism studies or newer theorizing within the field of anthropology (which, unfortunately, is often not dealing with tourism topics).

The second part contrasts the roles, views, and interests of the main stakeholders in Ngadha tourism and the conflicts between them: (1) mediators (government, guidebooks, and guides); (2) international tourists; and (3) Ngadha villagers. Full of detail, this vivid depiction of microlevel tourism dynamics, approached from multiple angles, gives the reader a real sense of 'being there'. An evocative example of the real-live implications of tourism fantasies is the contested presence of electricity poles in one of the villages. Dr. Cole describes how "the celebration of pre-electricity has worked against other villages getting electricity" (118). While both mediators and tourists are pushing villagers in the role of actors (whose behaviour is rule-governed or ruleoriented), local guides have become "agents of change" (121). Tourists are classified in diverse groups, "in order to develop a deeper understanding" (158). I would argue, however, that such a categorization does exactly the opposite. Typologies in general have been widely criticized by anthropologists because they lead to overgeneralization and do not allow for much 'thick description'. 
In the last section, the author discusses how tourism has affected the balance of power of the competing forces in the villagers' lives, examining the socio-cultural changes that have taken place over the last twenty years. Two villages are compared against each other. The author approaches the issue by placing the micro-level analysis again in a wider context. This is the beauty of her holistic approach: zooming in on the complexities of the local without loosing sight of influencing factors on provincial, national, and global levels. A good example of this is the short discussion of the measurable impact of western travel advisories in Ngadha (156).

The anthropological character of this work is most clearly visible in the attention Dr. Cole gives to the complex interaction between culture and tourism. Central in this discussion is the concept of adat - tradition or customary law. This notion "lies at the heart of this ethnography; it is one of the forces that shapes the villagers lives and how many conceptualise tradition" (49). The author nicely describes how adat has become contested and how tourism affects that contestation. What is traditional is now seen by the government to be attractive to tourists and therefore to be safeguarded. Thus, adat itself becomes contested. It is essential for attracting tourists, essential to the villagers' pride; "it lies at the heart of their new power in identity" (240).

In sum, this multi-sited and multi-temporal study is a welcome addition to the slowly growing list of tourism ethnographies. Written in a clear and perceptive style, avoiding academic jargon, this insightful work is meant to reach a wide audience. The large amount of background information makes it an excellent read for students and non-specialists interested in cultural tourism, anthropology, globalization, and Asian studies. Scholars, on the other hand, will be attracted by its longitudinal and comparative perspective.

Noel B. Salazar, Ph.D. Candidate, Department of Anthropology, University of Pennsylvania, University Museum Rm. 325, 3260 South Street, Philadelphia, PA 19104-6398, USA. Tel: +1-215898.7461; Fax: +1-215- 898.7462; E-mail: nsalazar@sas.upenn.edu. 